\title{
Anomalous Origin of the Right Coronary Artery from the Left Coronary Sinus in a child : case report
}

\author{
Neeraj Awasthy ${ }^{1}$ \\ ${ }^{1}$ Max Super Speciality Hospital Saket
}

April 28, 2020

\begin{abstract}
A 11 year-old boy with no relevant past cardiac history presented with complain of chest pain last 10 days . Electrocardiography showed sinus rhythm incomplete RBBB with no ST - T changes at rest ,Subsequent echo revealed abnormal origin of RCA with normal systolic and diastolic biventricular functions, CT- Coronary angiography finally confirmed the diagnosis and showed abnormal origin of right coronary artery that arose from the left coronary sinus- that has been associated with angina, myocardial infarction, and sudden cardiac death. The incidence of coronary anomalies in patients undergoing coronary angiography varies from $0.64 \%$ to $1.3 \%$. Many of these anomalies are clinically benign; however, others are associated with serious morbidity6. We describe the case of a patient in whom evaluation of chest pain revealed an anomalous right coronary artery arising from the left coronary sinus. We discuss the clinical importance of this anomaly and review the literature concerning current views and therapy.
\end{abstract}

\section{Introduction}

Coronary artery anomalies are defined as those angiographic findings in which the number, origin, course, and termination of these arteries are rarely encountered in the general population. ${ }^{1-3}$. An anomalous origin of the right coronary artery (RCA) from the left sinus is a very rare anomaly with incidence is $0.019 \%$ to $0.49 \%$ on coronary angiography. ${ }^{4}$ Accordingly, coronary artery anomalies are divided into those that cause and those that do not cause myocardial ischemia. Malignant features of anomalous coronaries include slit like ostium, an acute angle of takeoff, an intramural course, and significant compression between the aorta and the pulmonary trunk ${ }^{5}$.

\section{Case Report}

A 11 year-old male was referred to cardiology unit of our hospital from a general practitioner due to chest pain from last 10 days off and on not related to exertion not associated with sweating and non-radiating, there was no history of dyspnoea on effort, syncope, black out, palpitation at rest, and palpitation on activity. No family history of sudden death, angina or ischemic heart disease in family members. General and Physical examination was within normal limit. Laboratory examination showed normal value. Electrocardiogram at rest indicated sinus rhythm incomplete RBBB without sign of ischemia ( figure 1).

A non-invasive examination was performed with echocardiography. Transthoracic echocardiogram showed normal cardiac chamber dimension, normal right ventricle and left ventricle wall thickness, normal left and right ventricle systolic and diastolic function, and normal left ventricular segmental and global wall motion. Mitral valve and tricuspid valve were anatomically and functionally normal. Aortic valve examination showed three cusps with normal anatomy and function. Ostium and course of left coronary artery (LCA) was normal .Ostium of right coronary artery (RCA) was absent in normal position and coronary artery was arising anteriorly ( figure 2). There was no evidence of coronary artery compression. There no region wall motion abnormality. 
ECG gated CT coronary angiography confirmed anomalous origin of the right coronary artery (RCA) with high take off from the sino tubular junction above the left coronary cusp and short interarterial course $(1.5 \mathrm{~cm})$ between the ascending aorta and right ventricular outflow tract before reaching its usual position in the right atrio-ventricular groove. The origin was viewed in multiple views - there was no evidence of compression of the coronary artery, the origin of the vessel was circular in multiple views. The patient was diagnosed as abnormal right coronary from left sinus with inter-arterial course but with no evidence of compression. He was subjected to treadmill test, wherein he reached maximum predicted heart rate, without any evidence of ischemia or regional wall motion abnormality. No other structural cardiac abnormalities were found . Patient has been counselled to have regular follow up at 6 yearly interval. It is planned to subject him with stress test and thallium scan at regular intervals. He has been advocated to avoid competitive sports.

\section{Discussion}

Anomalous origin of the right coronary artery is a rare congenital anomaly that was 1st described in 1948 by White and Edwards ${ }^{7}$. The prevalence of this anomaly in the white population, as determined from autopsy studies, is $0.026 \% .{ }^{8}$ The prevalence of this anomaly in patients undergoing coronary angiography was $0.25 \%$ 9-10.

It is well established that an anomalous origin of the right coronary artery can lead to angina pectoris, myocardial infarction, or sudden death, in the absence of atherosclerosis ${ }^{11}$. The pathophysiologic basis for this association, however, is unclear. Mechanical compression of the right coronary artery by the great vessels is the usual explanation, because the anomalous right coronary artery generally courses between the aorta and the pulmonary artery to its normal position. Others have suggested that the oblique angle at the juncture of the anomalous right coronary artery and the left coronary sinus produces a slit-like orifice in the aortic wall that can collapse during exercise ${ }^{11}$ Recently, Kaku's group ${ }^{12}$ suggested that the proximal portion of the right coronary artery, situated between the aorta and the pulmonary artery, might be more prone to spasm than it would be otherwise.

Regardless of the causes of the adverse associations, there is a need to study prospectively those patients at highest risk. Moreover, the anomalous right coronary artery was 2nd only to the anomalous left main coronary artery as the cardiac anomaly ,most frequently associated with sudden cardiac death.

In an effort to stratify such cases by risk, Taylor and associates later (in 1997) ${ }^{13}$ performed a blinded pathologic analysis of 21 cases of anomalous origin of the right coronary artery. Despite reviewing a variety of anatomic variables (including ostial size, length of intramural course, angle of takeoff, and the presence of symptoms), this group found that only an age of 30 years or older was associated with a lower incidence of sudden cardiac death.

Understandably, the choice of treatment for this coronary anomaly is controversial, with some advocating revascularization in all cases. Proposed options include translocation of the right coronary artery to the aorta, ${ }^{14}$ ostioplasty (excision of the common wall between the right coronary artery and the aorta),${ }^{15}$ and bypass grafting of the right coronary artery (with optional ligation of the native artery proximal to the graft anastomosis to prevent competitive flow $)^{16}$. However, the long-term benefits of such therapies have not yet been demonstrated.

In Japan, treatment for this condition is more conservative. Kaku and associates ${ }^{17}$ studied 56 patients with an anomalous origin of a coronary artery and treated them medically with $\beta$-blockers. Approximately $9 \%$ of these patients experienced episodes of hypotension and arrhythmias on exertion, and no death was found to be directly related to the congenital anomaly during 5 years of follow-up.

With the available data, it would be good idea to subject them for illicitable ischemia . Any evidence of the risk factors such as oblique course, slit like opening and long abnormal course should err towards retranslocation. Otherwise, close monitoring with frequent evaluation for ilicitable ischemia as in our case may be a good alternative. Efforts can give rise to the large-scale studies needed to define the prognosis and optimal treatment of individual forms of coronary artery abnormality. 
Conclusion :-Coronary artery anomalies should be regarded as an uneven diverse group of congenital disorders whose manifestations and pathophysiological mechanisms are highly variable. This is a case report of rare coronary artery anomaly with interarterial course, without evidence of ischemic sign, in otherwise asymptomatic young boy. Watchful observation and strenuous activity restriction was applied in our case.

Reference:-

1. Ouali S, Neffeti E, Sendid K, et al: Congenital anomalous aortic origins of the coronary arteries in adults: A Tunisian coronary arteriography study. Arch Cardiovasc Dis 102:201, 2009.

2. Baskurt M, Yyldyz A, Caglar IM, et al: Right coronary artery arising from the pulmonary trunk. ThoracCardiovascSurg 57:424, 2009

3. Eckart RE, Jones SO, Shry EA, et al: Sudden death associated with anomalous coronary origin and obstructive coronary disease in the young. Cardiol Rev 14:161, 2006.

4. von Kodolitsch Y, Franzen O, Lund GK, et al: Coronary artery anomalies. Part II: recent

insights from clinical investigations. Z Kardiol 94:1, 2005.

5. Opolski MP, Pregowski J, Kruk M, et al: Prevalence and characteristics of coronary anoma-lies originating from the opposite sinus of Valsalva in 8,522 patients referred for coronary

computed tomography angiography. Am J Cardiol 111:1361, 2013

6. John S. Ho, MD and Neil E. Strickman, Anomalous Origin of the Right Coronary Artery from the Left Coronary Sinus, Tex Heart Inst J. 2002; 29(1): 37-39.

7. White NK, Edwards JE. Anomalies of the coronary arteries.Report of four cases. Arch Pathol 1948;45:76671. [PubMed]

8. Alexander RW, Griffiths GC.Anomalies of the coronary arteries and their clinical significance. Circulation 1956;14: 800-5. [PubMed]

9. Kaku B, Shimizu M, Yoshio H, Ino H, Mizuno S, Kanaya H, et al. Clinical features of prognosis of Japanese patients with anomalous origin of the coronary artery. JpnCirc J 1996;60:731-41. [PubMed]

10. Topaz O, DeMarchena EJ, Perin E, Sommer LS, Mallon SM, Chahine RA. Anomalous coronary arteries: angiographic findings in 80 patients. Int J Cardiol 1992;34:129-38. [PubMed]

11. Taylor AJ, Rogan KM, Virmani R. Sudden cardiac death associated with isolated congenital coronary artery anomalies. J Am CollCardiol 1992;20:640-7. [PubMed]

12. Kaku B, Kanaya H, Ikeda M, Uno Y, Fujita S, Kato F, Oka T. Acute inferior myocardial infarction and coronary spasm in a patient with an anomalous origin of the right coronary artery from the left sinus of Valsalva. JpnCirc J 2000;64: 641-3

13. Taylor AJ, Byers JP, Cheitlin MD, Virmani R. Anomalous right or left coronary artery from the contralateral coronary sinus: "high-risk" abnormalities in the initial coronary artery course and heterogeneous clinical outcomes. Am Heart J 1997;133:428-35.

14. Di Lello F, Mnuk JF, Flemma RJ, Mullen DC.Successful coronary reimplantation for anomalous origin of the right coronary artery from the left sinus of Valsalva. J ThoracCardiovascSurg 1991;102:455-6. [PubMed]

15. Rinaldi RG, Carballido J, Giles R, Del Toro E, Porro R. Right coronary artery with anomalous origin and slit ostium. Ann ThoracSurg 1994;58:829-32. [PubMed]

16. Shah AS, Milano CA, Lucke JP. Anomalous origin of the right coronary artery from the left coronary sinus: case report and review of surgical treatments. CardiovascSurg 2000;8:284-6. [PubMed] 
17. Kaku B, Shimizu M, Yoshio H, Ino H, Mizuno S, Kanaya H, et al. Clinical features of prognosis of Japanese patients with anomalous origin of the coronary artery. JpnCirc J 1996;60:731-41.

Legends:-

Figure 1: 12 lead ECG in the patient with abnormal right coronary artery from left sinus, showing no evidence of ischemia.

Figure 2: Parasternal short axis view showing the origin of right coronary artery from left sinus (marked by arrow). Ao: aorta, PA: pulmonary artery

Figure 3: CT coronary angiogram showing anomalous origin of right coronary artery from the anomalous sinus (marked by arrow). The original expected position of the coronary artery is marked by the star. Ao: aorta, RCA: right coronary artery.

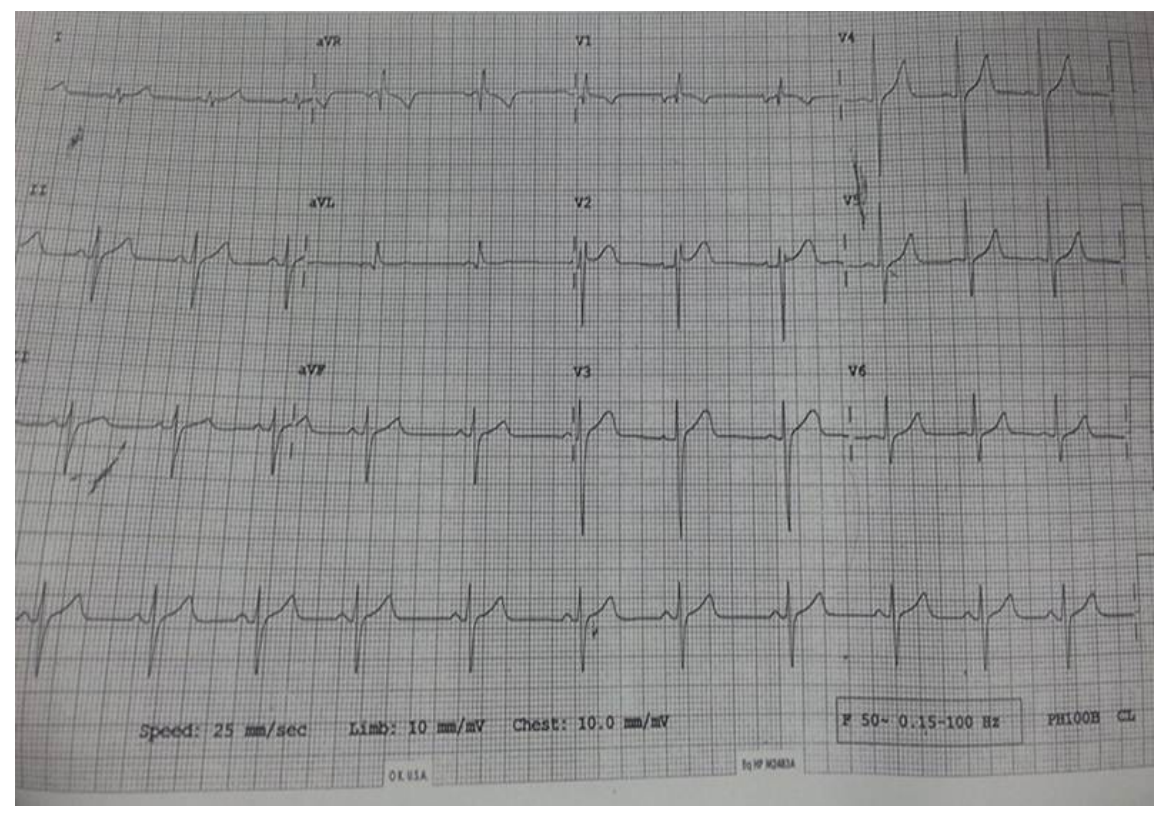



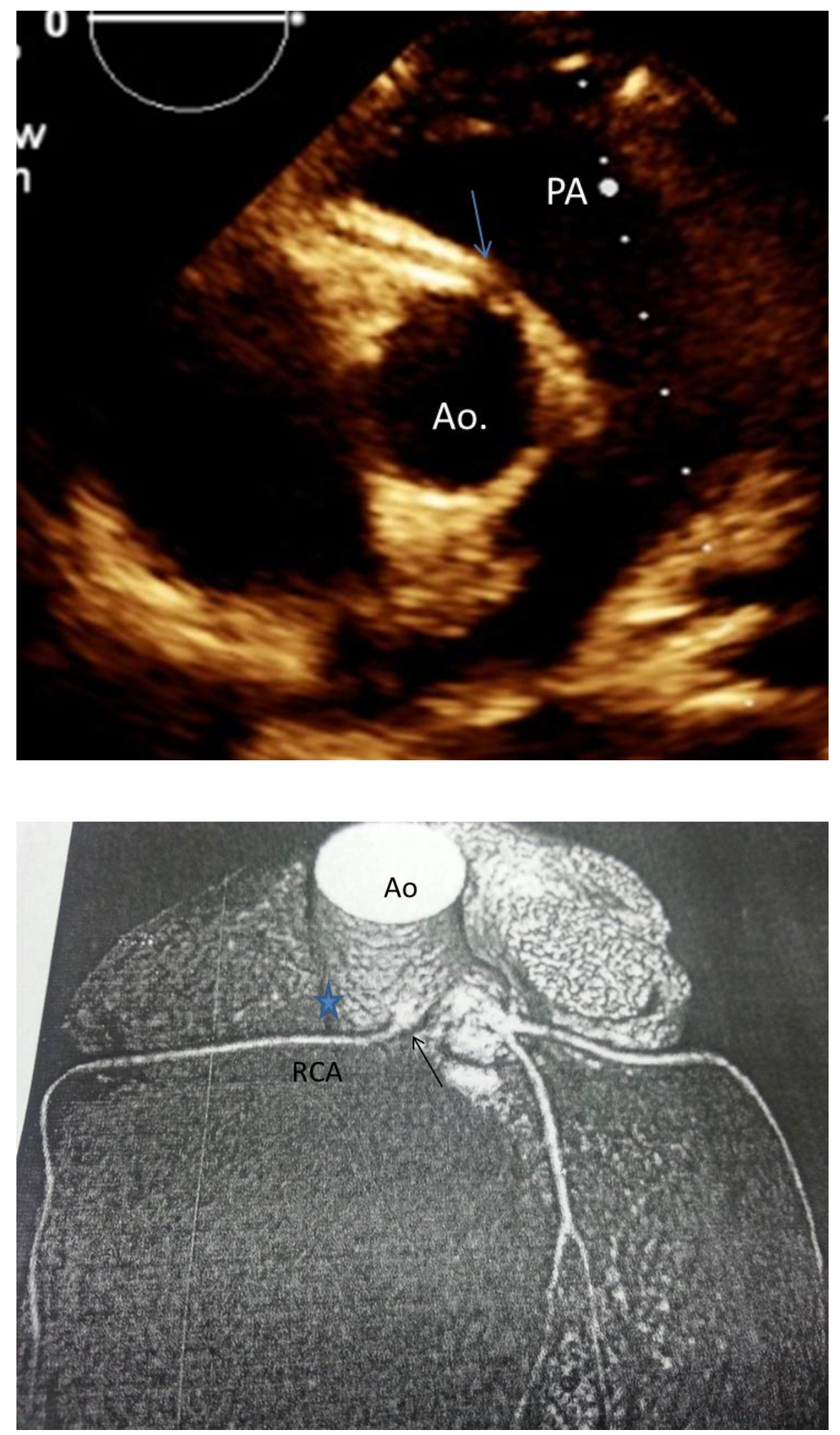